\title{
Correction to: Magnetic resonance imaging of medial collateral ligament avulsion fractures of the knee in children: a potentially underestimated injury
}

\author{
Delma Y. Jarrett ${ }^{1,2} \cdot$ Dennis E. Kramer $^{3} \cdot$ Tal Laor $^{1}$ \\ Published online: 29 May 2021 \\ (C) Springer-Verlag GmbH Germany, part of Springer Nature 2021
}

Correction to: Pediatric Radiology (2021).

https://doi.org/10.1007/s00247-021-05040-9

The original version of this paper included incorrect author affiliations. The correct affiliations are presented here.

The original article has been corrected.

Publisher's note Springer Nature remains neutral with regard to jurisdictional claims in published maps and institutional affiliations.

The online version of the original article can be found at https://oi.org/ 10.1007/s00247-021-05040-9

Delma Y. Jarrett

dej9009@med.cornell.edu

1 Department of Radiology, Boston Children's Hospital, Harvard Medical School, Boston, MA, USA

2 Department of Radiology, New York-Presbyterian Hospital, Weill Cornell Medicine, 525 E. 68th St., New York, NY 10065, USA

3 Department of Orthopedic Surgery, Boston Children's Hospital, Harvard Medical School, Boston, MA, USA 